\title{
Hybrid Metaheuristic-Neural Assessment of the Adhesion in Existing Cement Composites
}

\author{
Lukasz Sadowski $^{1, *}$, Mehdi Nikoo ${ }^{2}$ and Mohammad Nikoo ${ }^{3}$ \\ 1 Faculty of Civil Engineering, Wrocław University of Science and Technology, Wybrzeże Wyspiańskiego 27, \\ 50-370 Wrocław, Poland \\ 2 Young Researchers and Elite Club, Ahvaz Branch, Islamic Azad University, Ahvaz, Iran; \\ sazeh84@yahoo.com \\ 3 SAMA Technical and Vocational Training College, Islamic Azad University, Ahvaz Branch, Ahvaz, Iran; \\ m.nikoo2014@gmail.com \\ * Correspondence: lukasz.sadowski@pwr.edu.pl; Tel.: +48-71-320-37-42 \\ Academic Editor: Paul Lambert \\ Received: 29 December 2016; Accepted: 30 March 2017; Published: 1 April 2017
}

\begin{abstract}
The article presents the hybrid metaheuristic-neural assessment of the pull-off adhesion in existing multi-layer cement composites using artificial neural networks (ANNs) and the imperialist competitive algorithm (ICA). The ICA is a metaheuristic algorithm inspired by the human political-social evolution. This method is based solely on the use of ANNs and two non-destructive testing (NDT) methods: the impact-echo method (I-E) and the impulse response method (IR). In this research, the ICA has been used to optimize the weights of the ANN. The combined ICA-ANN model has been compared to the genetic algorithm (GA) and particle swarm optimization (PSO) to evaluate its accuracy. The results showed that the ICA-ANN model outperforms other techniques when testing datasets in terms of both effectiveness and efficiency. As presented in the validation stage, it is possible to reliably map the adhesion level on a tested surface without local damage to the latter.
\end{abstract}

Keywords: cement mortar; overlay; concrete substrate; interlayer bond; pull-off adhesion; artificial intelligence; metaheuristics; imperialist competitive algorithm; genetic algorithm; particle swarm optimization

\section{Introduction}

Layered cement composites, recently an issue attracting numerous researchers [1-4], usually consist of an overlay placed on an existing concrete substrate. It is always necessary to ensure an appropriate bond between the overlay and existing concrete substrate. The measure of this bond is the value of the pull-off adhesion $\left(f_{\mathrm{b}}\right)$, obtained using the pull-off method [5]. This method is time consuming due to the delay time of the curing of the resin used for bonding the steel disc. Moreover, results can be influenced by variation on the rupture surface, the orientation and position of the aggregate onto the disc, the disc material, diameter, and thickness, the backpressure system, and also the speed of load application [6-8]. The tested surface in each of the measuring places is damaged and the efficiency of this method depends on the number of measuring places. The damage has to be repaired after the test. When considering the above, it is advisable to use non-destructive testing (NDT) methods for the purpose of the assessment of the interlayer bond. It has been verified in practice that the impact-echo (I-E) and impulse response (IR) methods may be used individually to make a successful zero-one assessment $[9,10]$. However, it is not possible to individually use the above-mentioned NDT methods to make a full, reliable assessment of the value of $f_{\mathrm{b}}$ [11-13]. In such a 
case it is helpful to use artificial neural networks (ANNs) which, in recent years, are increasingly used in civil engineering [14-23].

A new method of identifying $f_{\mathrm{b}}$ by means of the ANN method has recently been proposed [24-29]. The database for this identification was created using 3D morphological parameters, which were evaluated on the existing concrete substrate surface using 3D LASER scanning, and also acoustic parameters obtained with the use of the IR and I-E methods on the surface of the overlay. Various methods have been used, such as radial basis functions (RBF) [24], multi-layer perceptron (MLP) [25-27], and principal component analysis (PCA), in combination with self-organizing feature maps (SOFM) [28].

It is evident that there is no possibility in existing layered cement composites of obtaining $3 \mathrm{D}$ morphological parameters of the existing concrete substrate surface. Consequently, it is not possible to adopt the previously-developed method to identify the value of $f_{\mathrm{b}}$ in existing cement composites. Thus, the attempt presented in [29] proved that it is possible to identify the value of $f_{\mathrm{b}}$ between the overlay and existing concrete substrate in existing cement composites on the basis of the acoustic parameters obtained on the overlay surface using the ANN, IR, and I-E methods. The multi-layer perceptron ANN with the gradient descent (MLP-GS) learning algorithm has been found to be useful for this purpose. However, values of determination coefficient $R^{2}$ greater than 0.77 were not satisfied. Simple back-propagation (BP) has also been used for optimizing the ANN, which is plagued with inconsistent and unpredictable performances, a slow learning rate, and becoming trapped in local minima [30,31]. Thus, in some applications it is necessary to improve the performance of the ANN with the use of optimization algorithms. The imperialist competitive algorithms (ICA), the genetic algorithm (GA), or particle swarm optimization (PSO) have recently been used for this purpose [32].

The recently developed ICA is a randomized population method inspired by the human political-social evolution [33-37]. It belongs to the metaheuristic group of methods that are expected to become more popular in various engineering applications [38-44]. In the ICA, a number of colonial countries, along with their colonies, try to find a general optimal point in solving the optimization problem. Different methods are then introduced to solve the optimization problems [45,46]. It is worth noting that there have recently been a few attempts to apply the ICA for engineering problems [47-49], e.g., the prediction of soil compaction [50], oil flow rate [51], optimum cost [52] or corrosion current density [53].

With consideration of the above, the article presents the hybrid metaheuristic-neural assessment of the value of the $f_{\mathrm{b}}$ in existing cement composites using the ICA. This method is based solely on the use of ANNs and two NDT methods: I-E and IR. In this research, the ANN was used for prediction and the ICA was used to improve the performance of the ANN. The role of the ICA was to optimize the weights of the ANN. The combined ICA-ANN model has been compared to the GA and PSO in order to evaluate its accuracy.

\section{Experimental Setup}

As mentioned previously in [29], the NDT tests were carried out on a surface of a two-layer cement composite with dimensions of $2500 \times 2500 \mathrm{~mm}^{2}$ and with a constant thickness of the overlay equal to $25 \mathrm{~mm}$ (Figure 1a,b). The overlay was made of C20/25 class cement mortar with the maximum quartz aggregate grain size equal to $2 \mathrm{~mm}$. The overlay was laid on the existing substrate with a constant thickness of $125 \mathrm{~mm}$ made of C30/37 class concrete. In this concrete, the maximum broken basalt aggregate grain size was equal to $8 \mathrm{~mm}$. The surface of the existing concrete substrate was sandblasted. In order to achieve a wider range of adhesion between the overlay and the substrate, half of the surface of the substrate was covered with a bonding agent in the form of concentrate to be diluted with water. Table 1 shows the weight composition of the mixes that were used to make the substrate and the overlay. 
a)

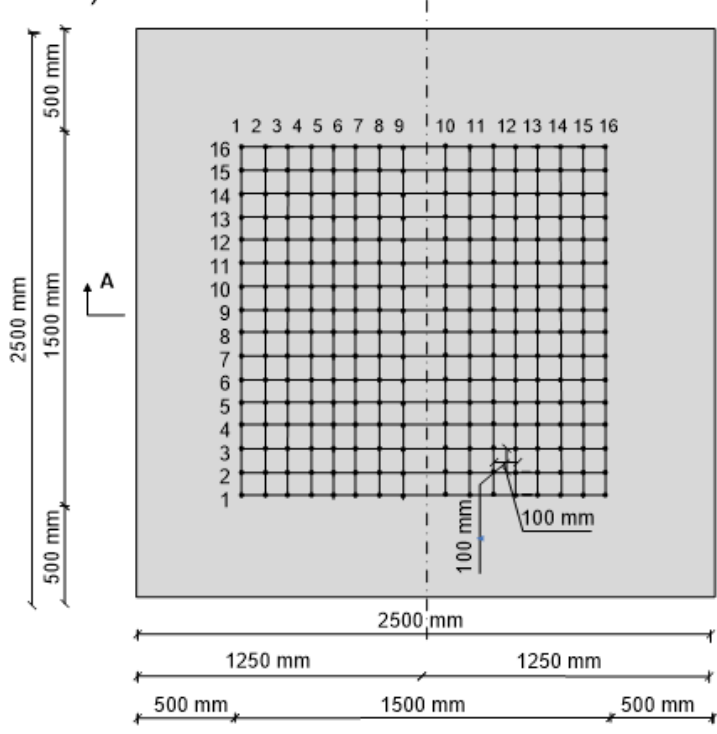

b)
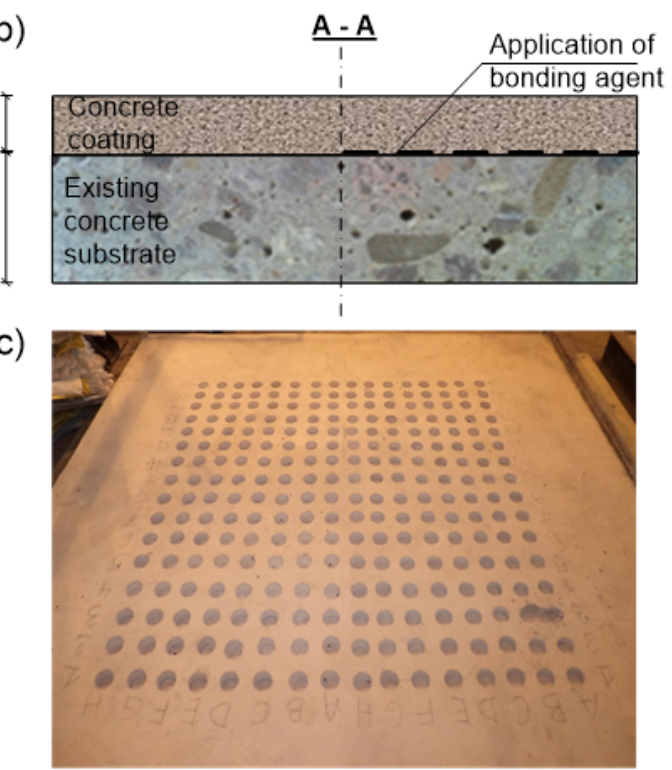

Figure 1. The tested two-layer cement composite: (a) arrangement of testing areas on the surface of the overlay; (b) cross-section; and (c) view of the surface of the overlay after pull-off testing.

Table 1. Weight composition of mixes.

\begin{tabular}{cccccccc}
\hline & \multicolumn{7}{c}{ Components of Mixes $\mathbf{( k g / \mathbf { m } ^ { 3 } )}$} \\
\cline { 2 - 8 } $\begin{array}{c}\text { Layer } \\
\text { Designation }\end{array}$ & $\begin{array}{c}\text { Portland } \\
\text { Cement CEM } \\
\text { I 42.5 R }\end{array}$ & $\begin{array}{c}\text { Portland } \\
\text { Cement CEM } \\
\text { II A-LL 42.5 R }\end{array}$ & Fly Ash & Water & $\begin{array}{c}\text { Fine } \\
\text { Aggregate } \\
\mathbf{0 - 2} \mathbf{~ m m}\end{array}$ & $\begin{array}{c}\text { Coarse } \\
\text { Aggregate } \\
\mathbf{2 - 8} \mathbf{~ m m}\end{array}$ & $\begin{array}{c}\text { Plasticizer } \\
\text { Visco } \\
\text { Flow 6920 }\end{array}$ \\
\hline Overlay & 276.0 & - & - & 138 & 1599.0 & - & - \\
\hline Substrate & - & 352.0 & 40 & 165 & 724.4 & 1086.6 & 2.0 \\
\hline
\end{tabular}

The grid of the testing areas was applied on the surface of the overlay $500 \mathrm{~mm}$ from its edge (Figure 1a) and the number of testing areas was equal to 256. 90 days after laying the overlay, tests using two acoustic NDT methods were carried out on its surface in 256 designated testing areas (Figure 2a,b).
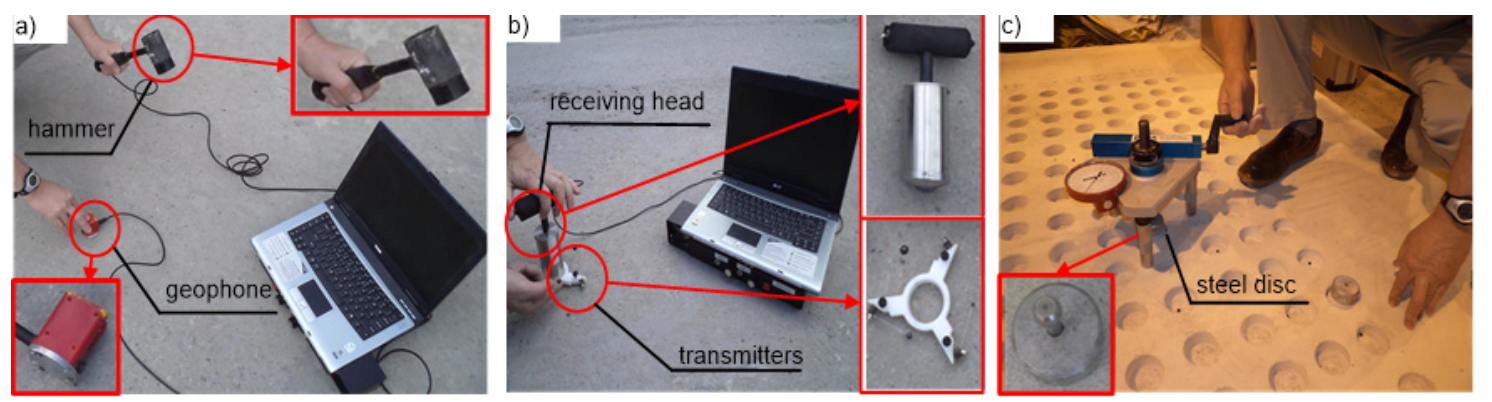

Figure 2. Exemplary view of tests carried out on the surface of the overlay using: (a) the IR method;

(b) the I-E method; and (c) the pull-off method.

The values of the following parameters were determined in all these areas using the IR method: average mobility $\left(N_{\mathrm{av}}\right)$, dynamic stiffness $\left(K_{\mathrm{d}}\right)$, mobility slope $\left(M_{\mathrm{p}} / N\right)$, and void index $(v)$ according to [54-56]. The value of the frequency of the sound wave reflection from the bottom of a sample $\left(f_{T}\right)$, obtained using the I-E method, was also measured according to [57-59].

After finishing the tests using acoustic NDT methods, tests using the pull-off method were conducted in the same testing areas in order to obtain the real values of the $f_{\mathrm{b}}$ (Figure $2 \mathrm{c}$ ). The $f_{\mathrm{b}}$ 
values were then used as patterns for learning and testing the ANN. The data used for development of the models was obtained from past experiments [29]. In this article, the output value of the pull-off adhesion predicted by the ANN is denoted as $f_{c, b}$. Exemplary data is presented in Table 2.

Table 2. Exemplary data.

\begin{tabular}{|c|c|c|c|c|c|c|}
\hline \multirow{3}{*}{$\begin{array}{c}\text { Number } \\
\text { of Test }\end{array}$} & \multicolumn{6}{|c|}{ Name of Test Method and Parameters } \\
\hline & \multicolumn{4}{|c|}{ The IR Method } & \multirow{2}{*}{$\begin{array}{c}\text { The I-E Method } \\
f_{\mathrm{T}}(\mathrm{kHz})\end{array}$} & \multirow{2}{*}{$\begin{array}{c}\text { The Pull-off Method } \\
f_{\mathrm{b}}(\mathrm{MPa})\end{array}$} \\
\hline & $N_{\mathrm{av}}(\mathrm{m} / \mathrm{s} \cdot \mathrm{N})$ & $K_{\mathrm{d}}$ & $M_{\mathrm{p}} / N$ & $v$ & & \\
\hline 1 & 155.000 & 0.002 & 0.503 & 3.149 & 13.20 & 1.044 \\
\hline 2 & 128.000 & 2.000 & 0.662 & 3.000 & 15.63 & 1.019 \\
\hline 3 & 79.000 & 2.000 & 1.413 & 1.000 & 12.20 & 1.070 \\
\hline 4 & 96.000 & 2.000 & 0.630 & 0.709 & 12.20 & 0.968 \\
\hline 5 & 80.000 & 1.000 & 0.740 & 1.040 & 12.60 & 0.891 \\
\hline 6 & 71.000 & 0.038 & 0.531 & 0.500 & 5.86 & 1.248 \\
\hline 7 & 92.000 & 1.000 & 0.612 & 0.629 & 15.14 & 1.095 \\
\hline 8 & 89.000 & 1.000 & 0.472 & 1.000 & 14.65 & 0.968 \\
\hline 9 & 103.000 & 1.000 & 0.661 & 0.689 & 12.21 & 1.070 \\
\hline 10 & 82.000 & 9.000 & 0.571 & 1.000 & 15.14 & 0.968 \\
\hline $\begin{array}{c}\ldots \\
256\end{array}$ & $\begin{array}{c}\ldots \\
108.065\end{array}$ & $\begin{array}{c}\ldots \\
1.000\end{array}$ & $\begin{array}{c}\ldots \\
1.825\end{array}$ & $\begin{array}{c}\ldots \\
1.000\end{array}$ & $\begin{array}{c}\ldots \\
14.65\end{array}$ & $\begin{array}{c}\ldots \\
0.866\end{array}$ \\
\hline
\end{tabular}

\section{Results of Training and Testing}

After applying the Chauvenet criterion of the elimination of questionable results and reducing the database to 239 sets of results, the resulting variables were randomly divided into ANN learning, testing, and experimental verification data. Once the data was normalized, out of 239 such sets of results, $70 \%$ of the samples (167 patterns) were randomly used for training and $15 \%$ of the selected samples (36 patterns) were randomly used to test the ANN. The rest of the samples were randomly used for validation (36 patterns). In order to include all the parameters in a numerical range and make the data dimensionless, the contributing input and output parameters should be normalized prior to the training phase according to Equation (1):

$$
x_{\mathrm{N}}=(x-\operatorname{Min} X) /(\operatorname{Max} X-\operatorname{Min} X) \times 2-1
$$

where $x_{\mathrm{N}}$ is the normalized input and output data, $x$ is the input data, Min $X$ is the minimum of all data, and MaxX is the maximum of all data. Therefore, all of the normalized data is placed in the numerical distance of $[-1,+1]$. The hidden layer node numbers were determined according to [60] by using Equation (2):

$$
N_{H} \leq 2 N_{I}+1
$$

where $N_{\mathrm{H}}$ is the maximum number of neurons in the hidden layers and $N_{\mathrm{I}}$ is the number of inputs. Considering that the number of effective inputs obtained is 5 , the maximum number of nodes in the hidden layer is equal to 11 .

The ICA is used to determine the optimized weight of each of the ANN models. The structure of the ICA-ANN used in the analysis is presented in Figure 3. Table 3 indicates the optimized structure of each model along with features of the ICA. Furthermore, Table 4 indicates the analytical results of training and testing each of the models with optimal structure, which is provided in Table 3. Five statistical parameters of mean error $(M E)$, mean absolute error $(M A E)$, mean squared error $(M S E)$, root mean squared error (RMSE), and mean squared reduced error (MSRE) are presented in Table 5. The performance measurements from all models have been collected and averaged. Due to the randomness of weights and data sampling, each experiment is simulated ten times in order to obtain more reliable results. To determine the performance of the models and to decide on the best model, the MSE test and MSE training criteria obtained from the models are compared with each other and shown in Table 3. According to the indicated results, the 250GEN_5IN model, the weight of which has 
been optimized by the ICA, has been optimized by 500 countries, 50 empires, and 250 repetitions, and has the best results among the models of its kind.

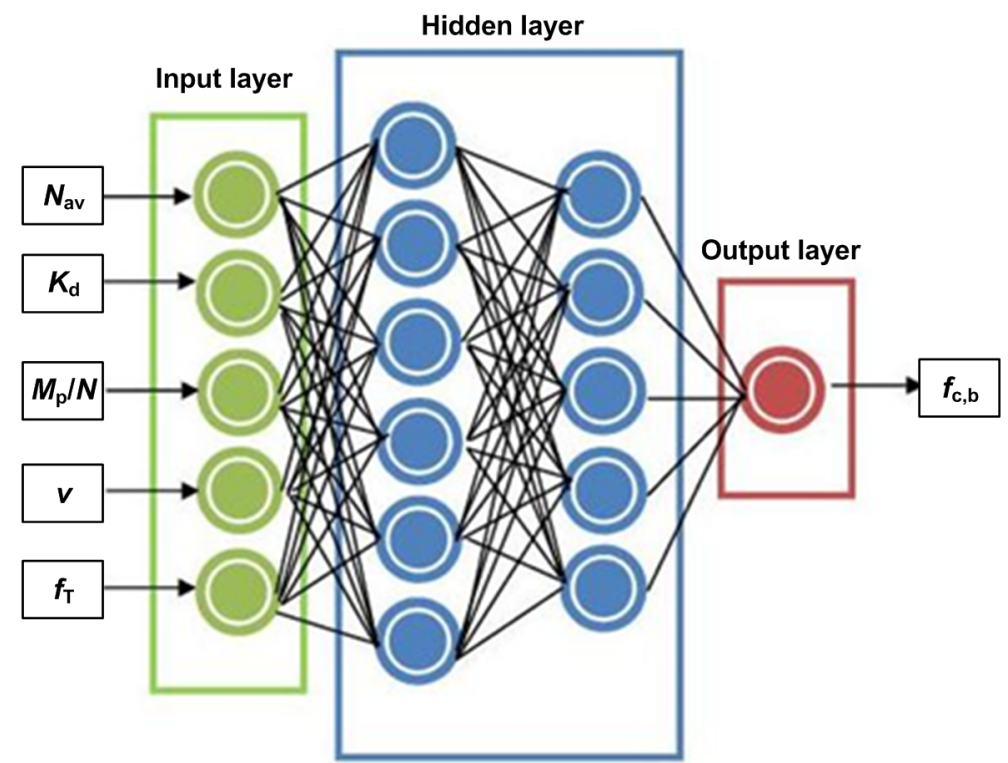

Figure 3. The structure of the ICA-ANN used in the analysis.

Table 3. Optimized structure of the ICA-ANN.

\begin{tabular}{|c|c|c|c|c|c|c|c|c|}
\hline \multirow[b]{2}{*}{$\begin{array}{l}\text { Models } \\
\text { Name }\end{array}$} & \multicolumn{5}{|c|}{ ANN Features } & \multicolumn{3}{|c|}{$\begin{array}{l}\text { Utilized Initialization } \\
\text { Parameters in the ICA }\end{array}$} \\
\hline & $\begin{array}{l}\text { Number } \\
\text { of Input }\end{array}$ & $\begin{array}{l}\text { Number } \\
\text { of } \\
\text { Output }\end{array}$ & $\begin{array}{l}\text { Number of } \\
\text { Hidden } \\
\text { Layer }\end{array}$ & $\begin{array}{l}\text { Number of } \\
\text { Neurons in } \\
\text { Hidden Layer }\end{array}$ & $\begin{array}{l}\text { Transfer } \\
\text { Function }\end{array}$ & $\begin{array}{l}\text { Number } \\
\text { of } \\
\text { Country }\end{array}$ & $\begin{array}{l}\text { Number } \\
\text { of } \\
\text { Imperialist }\end{array}$ & $\begin{array}{c}\text { Number } \\
\text { of } \\
\text { Decades }\end{array}$ \\
\hline 50GEN_5IN & 5 & 1 & 1 & 13 & satlins & 400 & 40 & 50 \\
\hline 200GEN_5IN & 5 & 1 & 3 & $6-4-3$ & satlins & 500 & 50 & 200 \\
\hline 250GEN_5IN & 5 & 1 & 2 & $6-5$ & tansig & 500 & 50 & 250 \\
\hline
\end{tabular}

Table 4. Results of testing and training of the ICA-ANN.

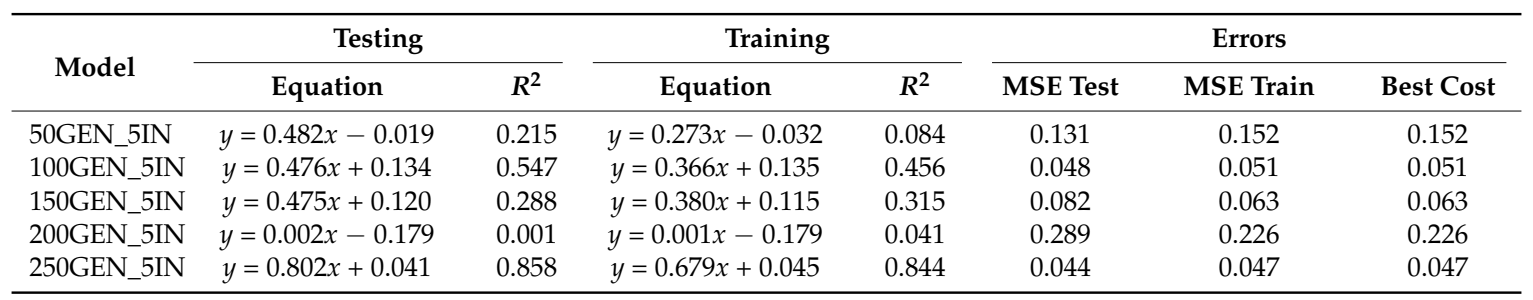

Table 5. Statistical results of ICA-ANN errors.

\begin{tabular}{|c|c|c|c|c|c|c|c|c|c|c|}
\hline \multirow{2}{*}{ Model } & \multicolumn{2}{|c|}{$M E$} & \multicolumn{2}{|c|}{$M A E$} & \multicolumn{2}{|c|}{ MSE } & \multicolumn{2}{|c|}{ RMSE } & \multicolumn{2}{|c|}{ MSRE } \\
\hline & Train & Test & Train & Test & Train & Test & Train & Test & Train & Test \\
\hline 50GEN_5IN & -0.169 & -0.153 & 0.308 & 0.270 & 0.151 & 0.128 & 0.389 & 0.357 & 1.648 & 1.346 \\
\hline 100GEN_5IN & 0.016 & -0.001 & 0.158 & 0.148 & 0.051 & 0.043 & 0.227 & 0.208 & 0.560 & 0.455 \\
\hline 150GEN_5IN & -0.001 & -0.012 & 0.184 & 0.198 & 0.064 & 0.077 & 0.252 & 0.278 & 0.693 & 0.815 \\
\hline 200GEN_5IN & -0.367 & -0.438 & 0.399 & 0.458 & 0.226 & 0.286 & 0.475 & 0.535 & 2.459 & 3.011 \\
\hline 250GEN_5IN & -0.015 & -0.010 & 0.104 & 0.094 & 0.017 & 0.014 & 0.131 & 0.117 & 0.188 & 0.144 \\
\hline
\end{tabular}


As indicated in Tables 3 and 4, in model 5 the values of the determination coefficient $R^{2}$ for the parameter of $f_{\mathrm{b}}$ at the training and testing stages are equal, respectively, to 0.844 and 0.858 . The slope of the straight line for this parameter equals 0.679 and 0.802 , which represents the accuracy of the model and less modeling error. According to [61], in this model the nonlinear tan-sigmoid function (TANSIG), which shows the minimal error, was considered as the transfer function:

$$
\operatorname{Tansig}(n)=\frac{2}{1+\mathrm{e}^{-2 n}}-1
$$

According to Table 5, the coefficients of $M E, M A E, M S E, R M S E$, and MSRE in two training and testing stages for the ANN model with a 1-5-6-5 structure, and also the properties of 500 countries, 50 empires, and 250 repetitions, are less than for all of the other models. This represents lower errors of this ANN in comparison to other models. Therefore, the ICA-ANN model with the title of 250GEN_5IN is more accurate than other models of its kind. The result of comparing the selected 250GEN_5IN ICA-ANN model with the observation data is presented in Figure 4. The minimum cost and the mean cost diagrams are shown in Figure 5.

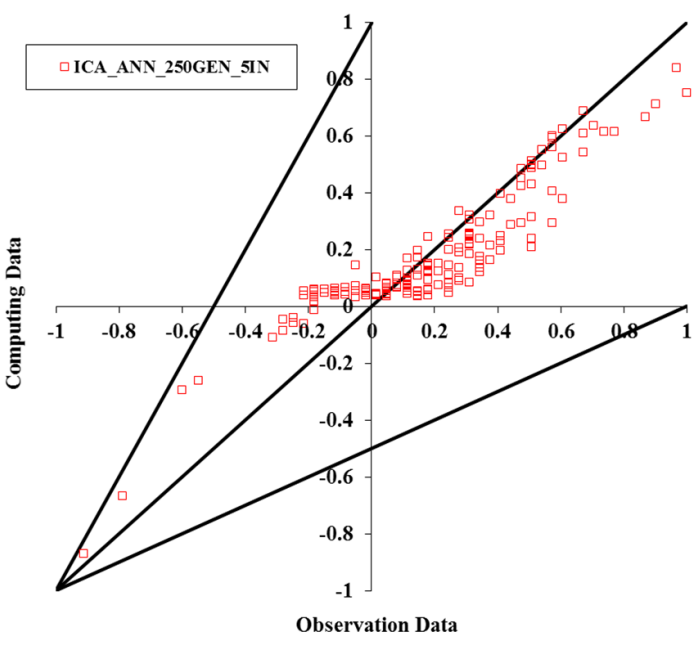

(a)

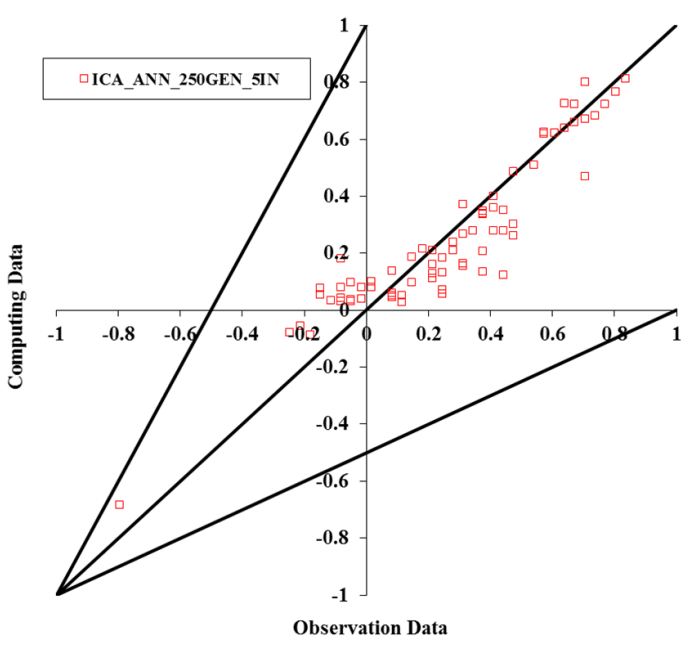

(b)

Figure 4. Results of the ICA-ANN for (a) training and (b) testing.

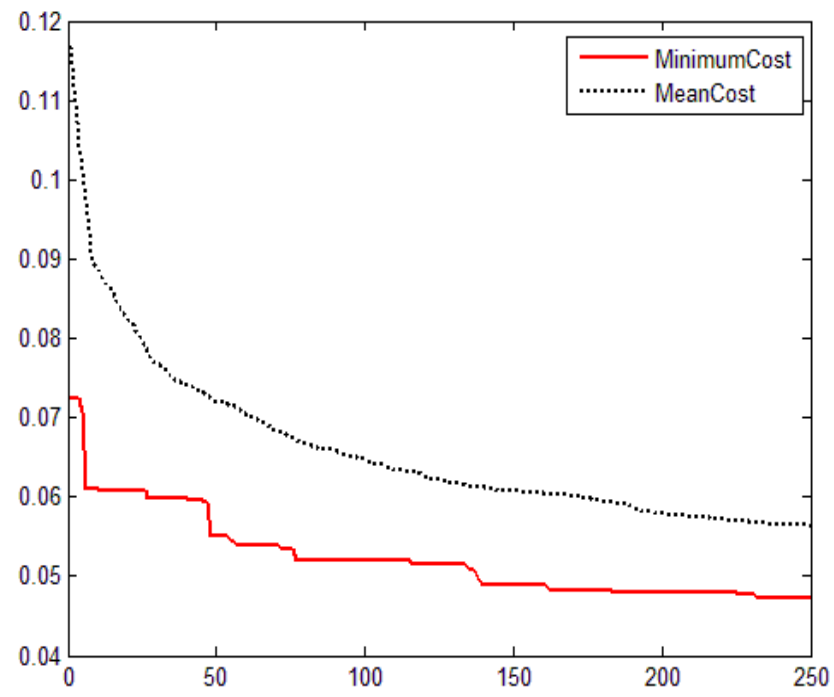

Figure 5. Graph cost for 250 iterations in the 250GEN_5IN model. 


\section{Comparison with the Genetic Algorithm (GA) and Particle Swarm Optimization (PSO)}

In order to evaluate the accuracy of the ICA-ANN model, which has been optimized by the ICA, it was compared with both the GA and PSO, the features of which are provided in Table 6 . The ICA-ANN model with a 1-5-6-5 structure and the TANSIG stimulation function were used. According to a study conducted on three algorithms for training data and testing, $R^{2}$ coefficients and the slope of the straight line are presented in Table 7. Figure 5 shows graph cost for 250 iterations in the 250GEN_5IN model. Figure 6 shows the comparison of the $f_{\mathrm{b}}$ values for the computational and observational data using the three algorithms in the training stage. According to the equations of lines fitted to the computational and observational values in each model, and also the coefficient of determination that corresponds to them (Table 7), it can be seen that the ANN optimized by the ICA determines the amount of $f_{\mathrm{b}}$ more accurately than the GA and PSO algorithms. Moreover, the determination of $f_{\mathrm{b}}$ using the three models shown in Figure 6 indicates that the ANN optimized by the ICA has higher accuracy and flexibility.

Table 6. Applied GA, ICA, and PSO parameters.

\begin{tabular}{|c|c|c|c|c|c|}
\hline \multicolumn{2}{|c|}{ GA } & \multicolumn{2}{|l|}{ ICA } & \multicolumn{2}{|l|}{ PSO } \\
\hline Population & 150 & Countries & 500 & \multirow{2}{*}{ Swarm Size } & \multirow{2}{*}{200} \\
\hline Mutation rate & 15 & Revolution Rate & 0.3 & & \\
\hline \multirow{2}{*}{ Crossover rate } & \multirow{2}{*}{50} & Empires & 50 & Cognition Coefficient & 2 \\
\hline & & Uniting threshold & 0.02 & Social Coefficient & 2 \\
\hline Generation & 250 & Generation & 250 & Generation & 250 \\
\hline
\end{tabular}

Table 7. Results of ANN models optimized by the GA, ICA, and PSO algorithms in training and testing.

\begin{tabular}{|c|c|c|c|c|c|c|c|}
\hline \multirow{2}{*}{ Model } & \multicolumn{2}{|c|}{ Best Fitting Line in Testing } & \multicolumn{2}{|c|}{ Best Fitting Line in Training } & \multicolumn{3}{|c|}{ Errors } \\
\hline & Equation & $R^{2}$ & Equation & $R^{2}$ & MSE Test & MSE Train & Best Cost \\
\hline ICA-ANN & $y=0.802 x+0.041$ & 0.858 & $y=0.679 x+0.045$ & 0.844 & 0.044 & 0.047 & 0.047 \\
\hline GA-ANN & $y=-0.010 x+0.240$ & 0.000 & $y=0.035 x+0.200$ & 0.003 & 0.076 & 0499 & 0.049 \\
\hline PSO-ANN & $y=0.612 x+0.089$ & 0.530 & $y=0.485 x+0.095$ & 0.506 & 0.050 & 0.045 & 0.045 \\
\hline
\end{tabular}

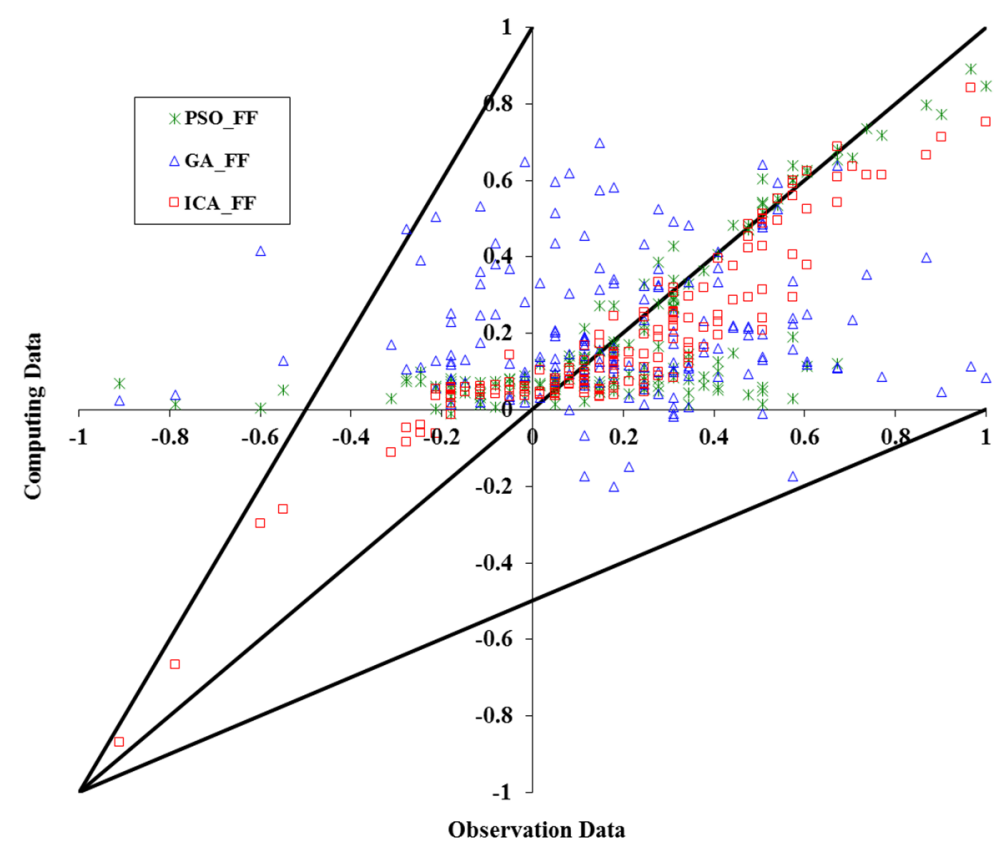

(a)

Figure 6. Cont. 


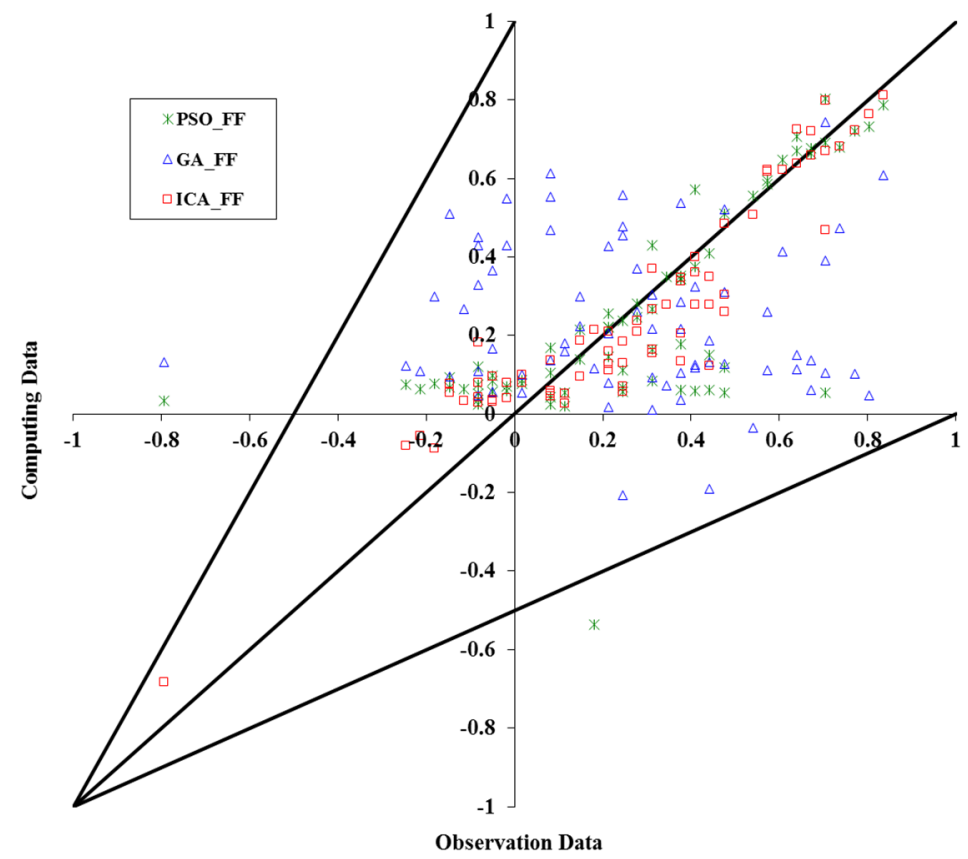

(b)

Figure 6. Comparison of the selected ICA-ANN with GA-ANN and PSO-ANN in (a) training and (b) testing.

\section{Results of Validation of the Proposed ICA-ANN Model}

In order to conduct the validation of the ICA-ANN model, a set of 36 results was randomly selected. These results were not previously used to train and test the ICA-ANN. As a result, the taught ICA-ANN model generated the value of the pull-off adhesion for each of these areas. Table 8 presents a comparative summary of the values of $f_{\mathrm{b}}$ and $f_{\mathrm{c}, \mathrm{b}}$, defined, respectively, using the pull-off method and ICA-ANN.

Table 8. Comparative summary of the values of $f_{\mathrm{b}}$ and $f_{\mathrm{c}, \mathrm{b}}$, defined using the pull-off method and ICA-ANN, respectively.

\begin{tabular}{|c|c|c|c|c|c|c|c|c|c|c|c|c|c|c|}
\hline \multirow{2}{*}{ No. } & $f_{\mathrm{b}}$ & $f_{\mathrm{c}, \mathrm{b}}$ & $|\Delta f|$ & $|R E|$ & \multirow{2}{*}{ No. } & $f_{\mathrm{b}}$ & $f_{\mathrm{c}, \mathrm{b}}$ & $|\Delta f|$ & $|R E|$ & \multirow{2}{*}{ No. } & \multirow{2}{*}{$\frac{f_{\mathrm{b}}}{\mathrm{MPa}}$} & \multirow{2}{*}{$\frac{f_{\mathrm{c}, \mathrm{b}}}{\mathrm{MPa}}$} & \multirow{2}{*}{$\begin{array}{l}|\Delta f| \\
\mathrm{MPa}\end{array}$} & \multirow{2}{*}{$\frac{|R E|}{\%}$} \\
\hline & MPa & $\mathrm{MPa}$ & MPa & $\%$ & & MPa & $\mathrm{MPa}$ & MPa & $\%$ & & & & & \\
\hline 1 & 1.30 & 1.29 & 0.01 & $0.85 \%$ & 13 & 1.06 & 1.06 & 0.01 & $0.56 \%$ & 25 & 1.55 & 1.42 & 0.13 & $9.09 \%$ \\
\hline 2 & 1.13 & 1.08 & 0.04 & $4.16 \%$ & 14 & 1.04 & 1.06 & 0.02 & $1.46 \%$ & 26 & 1.19 & 1.19 & 0.00 & $0.25 \%$ \\
\hline 3 & 1.50 & 1.40 & 0.10 & $7.06 \%$ & 15 & 1.21 & 1.19 & 0.03 & $2.12 \%$ & 27 & 1.23 & 1.12 & 0.11 & $10.01 \%$ \\
\hline 4 & 1.26 & 1.18 & 0.08 & $6.83 \%$ & 16 & 1.01 & 1.05 & 0.04 & $4.13 \%$ & 28 & 1.07 & 1.07 & 0.00 & $0.28 \%$ \\
\hline 5 & 1.21 & 1.12 & 0.09 & $7.82 \%$ & 17 & 0.92 & 1.06 & 0.14 & $13.13 \%$ & 29 & 1.19 & 1.17 & 0.03 & $2.44 \%$ \\
\hline 6 & 0.62 & 0.68 & 0.06 & $9.25 \%$ & 18 & 1.02 & 1.06 & 0.04 & $3.52 \%$ & 30 & 1.06 & 1.06 & 0.00 & $0.20 \%$ \\
\hline 7 & 1.18 & 1.13 & 0.05 & $4.10 \%$ & 19 & 0.95 & 1.06 & 0.11 & $10.16 \%$ & 31 & 0.95 & 1.06 & 0.10 & $9.60 \%$ \\
\hline 8 & 1.30 & 1.16 & 0.14 & $12.10 \%$ & 20 & 1.02 & 1.06 & 0.04 & $3.86 \%$ & 32 & 1.11 & 1.10 & 0.01 & $0.79 \%$ \\
\hline 9 & 1.16 & 1.07 & 0.09 & $8.07 \%$ & 21 & 1.30 & 1.29 & 0.00 & $0.32 \%$ & 33 & 1.21 & 1.16 & 0.05 & $4.68 \%$ \\
\hline 10 & 0.56 & 0.58 & 0.02 & $3.71 \%$ & 22 & 1.13 & 1.16 & 0.03 & $2.90 \%$ & 34 & 1.11 & 1.05 & 0.06 & $5.63 \%$ \\
\hline 11 & 1.09 & 1.08 & 0.01 & $1.23 \%$ & 23 & 1.33 & 1.34 & 0.01 & $0.98 \%$ & 35 & 0.94 & 1.05 & 0.11 & $10.89 \%$ \\
\hline 12 & 1.06 & 1.06 & 0.01 & $0.52 \%$ & 24 & 0.97 & 1.06 & 0.09 & $8.31 \%$ & 36 & 1.30 & 1.29 & 0.01 & $0.85 \%$ \\
\hline- & - & - & - & - & - & - & - & - & - & Mean & 1.11 & 1.11 & 0.05 & $4.50 \%$ \\
\hline
\end{tabular}

The results of validation presented in Table 8 indicate the correct identification of validation data. It is evidenced by the obtained low mean value of the absolute error amounting to $0.05 \mathrm{MPa}$ and the satisfactory mean value of the relative error $|R E|$ amounting to $4.89 \%$. Interestingly, the values of $f_{\mathrm{c}, \mathrm{b}}$ identified by the ICA-ANN are equal to $1.11 \mathrm{MPa}$ and are, on average, the same as the $f_{\mathrm{b}}$ obtained 
experimentally using the pull-off method. The results of the validation were used to plot the adhesion maps shown in Figure 7 (results in the other points on the tested surface were obtained by means of linear interpolation). This figure illustrates two adhesion maps. The first one was obtained on the basis of experimental tests conducted using the pull-off method (Figure 7a). The second one was identified by the ICA-ANN.

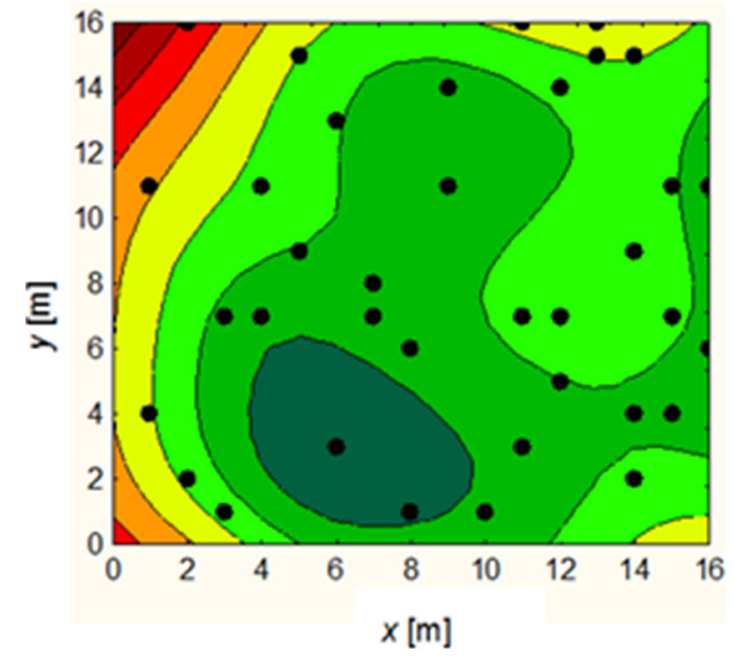

(a)

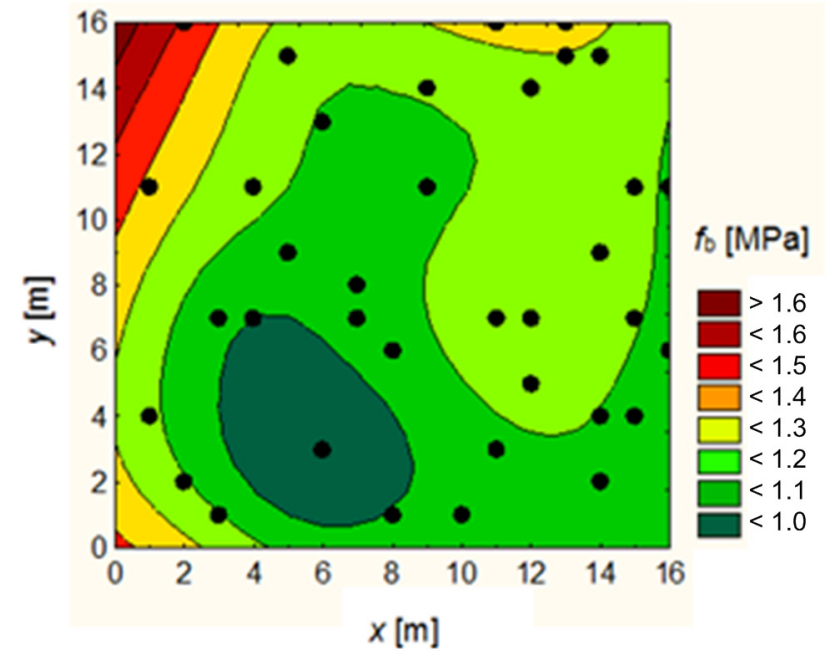

(b)

Figure 7. Comparative maps of the value of the $f_{\mathrm{b}}$, based on validation results yielded by: (a) the pull-off method; (b) the ICA-ANN model (the symbol "•" represents a randomly-selected test point used for validation).

\section{Conclusions}

The results of the proposed hybrid method indicate that the metaheuristic ICA is successful in optimizing the ANN. The prediction model requires knowledge of a total of five parameters: $K_{\mathrm{d}}, N_{\mathrm{av}}$, $M_{\mathrm{p}} / N$, and $v$, obtained using the IR method, and also parameter $f_{\mathrm{T}}$, which was obtained using the I-E method. ANN with a 1-5-6-5 structure with the nonlinear tan-sigmoid transfer function and the properties related to the ICA with 500 countries and 50 primary empires and 250 repetitions has a higher ability and accuracy in determining the value of the $f_{\mathrm{b}}$.

In the best ANN model, optimized by the ICA for determining the value of the $f_{\mathrm{b}}$, the determination coefficient $R^{2}$ at the stages of training and testing is 0.844 and 0.858 , respectively. The results indicated that the ICA-ANN model outperforms the other methods, such as the GA and PSO. The $R^{2}$ values are also higher than those obtained previously by the simple MLP-ANN [29]. The obtained values of $R^{2}$ can be considered as satisfactory, taking into account the fact that it is not necessary to use the 3D roughness parameters of an existing concrete substrate surface.

Various functional issues solved by this algorithm also indicate that the proposed optimization strategy can successfully help to solve practical problems. The pull-off adhesion of the cement mortar in the existing concrete substrate in real cement composites can be obtained with the use of the proposed method. However, this method is applicable when the thicknesses of the layers of the cement mortar and substrate, and also the composition of the cement mortar and existing concrete substrate in the particular cement composite, are similar to the ones that were used to create the database in this article. Otherwise, it is necessary to create a new database for cement composites that are tested in practice.

Acknowledgments: This work was supported by the National Centre of Science, Poland (grant no. 2014/15/D/ST8/00550 "Evaluation of the interlayer bond of variably thick concrete layers based on nondestructive tests using artificial intelligence"). 
Author Contributions: Łukasz Sadowski conceived and designed the experiments; Mehdi Nikoo and Mohammad Nikoo performed the numerical analysis; Łukasz Sadowski analyzed the data; Łukasz Sadowski, Mehdi Nikoo and Mohammad Nikoo wrote the paper.

Conflicts of Interest: The authors declare no conflict of interest. The founding sponsors had no role in the design of the study; in the collection, analyses, or interpretation of data; in the writing of the manuscript, and in the decision to publish the results.

\section{References}

1. Ranjbar, N.; Behnia, A.; Chai, H.K.; Alengaram, J.; Jumaat, M.Z. Fracture evaluation of multi-layered precast reinforced geopolymer-concrete composite beams by incorporating acoustic emission into mechanical analysis. Constr. Build. Mater. 2016, 127, 274-283. [CrossRef]

2. Szemerey-Kiss, B.; Török, Á. Failure mechanisms of repair mortar stone interface assessed by pull-off strength tests. Bull. Eng. Geol. Environ. 2017, 76, 159-167. [CrossRef]

3. Niwa, J.; Matsumoto, K.; Sato, Y.; Yamada, M.; Yamauchi, T. Experimental study on shear behavior of the interface between old and new deck slabs. Eng. Struct. 2016, 126, 278-291. [CrossRef]

4. Wu, J.; Liu, X.; Chew, S.H. Parametric study on cement-based soft-hard-soft (SHS) multi-layer composite pavement against blast load. Constr. Build. Mater. 2015, 98, 602-619. [CrossRef]

5. EN 12504-3. Analysis of Concrete in Constructions. Part 3: Determination of the Pull-out Force; Polish Committee for Standardization: Warsaw, Poland, 2006.

6. Pereira, E.; de Medeiros, M.H.F. Pull-off test to evaluate the compressive strength of concrete: An alternative to Brazilian standard techniques. Rev. IBRACON Estrut. Mater. 2012, 5, 757-780. [CrossRef]

7. Momayez, A.; Ehsani, M.; Ramezanianpour, A.A.; Rajaie, H. Comparison of methods for evaluating bond strength between concrete substrate and repair materials. Cem. Concr. Res. 2005, 35, 748-757. [CrossRef]

8. Bungey, J.; Madandoust, R. Factors influencing pull-off tests on concrete. Mag. Concr. Res. 1992, 44, 21-30. [CrossRef]

9. Hoła, J.; Sadowski, Ł.; Schabowicz, K. Nondestructive identification of delaminations in concrete floor toppings with acoustic methods. Autom. Constr. 2011, 20, 799-807. [CrossRef]

10. Hoła, J.; Sadowski, Ł.; Schabowicz, K. Nondestructive assessment of the adhesion of concrete screeds in the ventilating ducts of mine shafts. In Proceedings of the 11th European Conference on Non-Destructive Testing (ECNDT 2014), Prague, Czech Republic, 6-10 October 2014.

11. Hoła, J.; Sadowski, $€$. Testing interlayer pull-off adhesion in concrete floors by means of nondestructive acoustic methods. In Proceedings of the 18th World Conference on Non Destructive Testing, Durban, South Africa, 16-20 April 2012.

12. Sadowski, $€$. Nondestructive evaluation of interlayer bond in floors by using artificial neural networks. Ph.D. Thesis, Wrocław University of Science and Technology, Wrocław, Poland, 2012.

13. Sadowski, $€$. Analysys of the effect of concrete base roughness on the pull-off adhesion of the topping layer. IAPGOŚ 2013, 1, 39-42. (In Polish)

14. Veiskarami, M.; Ghorbani, A.; Alavipour, M. Development of a constitutive model for rockfills and similar granular materials based on the disturbed state concept. Front. Struct. Civ. Eng. 2012, 6, 365-378.

15. Cheng, M.Y.; Tran, D.H.; Hoang, N.D. Fuzzy clustering chaotic-based differential evolution for resource leveling in construction projects. J. Civ. Eng. Manag. 2017, 23, 113-124. [CrossRef]

16. Kaloop, M.R.; Hu, J.W. Optimizing the De-Noise neural network model for GPS time-series monitoring of structures. Sensors 2015, 15, 24428-24444. [CrossRef] [PubMed]

17. Talaei, A.S.; Nasrollahi, A.; Ghayekhloo, M. An automated approach for optimal design of prestressed concrete slabs using PSOHS. KSCE J. Civ. Eng. 2017, 21, 782-791. [CrossRef]

18. Li, X.; Qiu, J.; Shang, Q.; Li, F. Simulation of Reservoir Sediment Flushing of the Three Gorges Reservoir Using an Artificial Neural Network. Appl. Sci. 2016, 6, 148. [CrossRef]

19. Kaveh, A.; Talaei, A.S.; Nasrollahi, A. Application of Probabilistic Particle Swarm in Optimal Design of Large-Span Prestressed Concrete Slabs. Iran. J. Sci. Technol. Trans. Civ. Eng. 2016, 40, 33-40. [CrossRef]

20. Zhang, J.K.; Yan, W.; Cui, D.M. Concrete Condition Assessment Using Impact-Echo Method and Extreme Learning Machines. Sensors 2016, 16, 447. [CrossRef] [PubMed]

21. Tran, T.H.; Hoang, N.D. Predicting Colonization Growth of Algae on Mortar Surface with Artificial Neural Network. J. Comput. Civ. Eng. 2016, 30, 04016030. [CrossRef] 
22. Khademi, F.; Jamal, S.M.; Deshpande, N.; Londhe, S. Predicting strength of recycled aggregate concrete using Artificial Neural Network, Adaptive Neuro-Fuzzy Inference System and Multiple Linear Regression. Int. J. Sustain. Built Environ. 2016, 5, 355-369. [CrossRef]

23. Hasanzadehshooiili, H.; Lakirouhani, A.; Medzvieckas, J. Superiority of artificial neural networks over statistical methods in prediction of the optimal length of rock bolts. J. Civ. Eng. Manag. 2012, 18, 655-661. [CrossRef]

24. Sadowski, $€$. Non-destructive evaluation of the pull-off adhesion of concrete floor layers using RBF neural Network. J. Civ. Eng. Manag. 2013, 19, 550-560. [CrossRef]

25. Sadowski, Ł.; Hoła, J. New non-destructive way of identifying the values of pull-off adhesion between concrete layers in floors. J. Civ. Eng. Manag. 2014, 20, 561-569. [CrossRef]

26. Sadowski, $€$. Non-destructive identification of pull-off adhesion between concrete layers. Autom. Constr. 2015, 57, 146-155. [CrossRef]

27. Sadowski, Ł.; Hoła, J. ANN modeling of pull-off adhesion of concrete layers. Adv. Eng. Softw. 2015, 89, 17-27. [CrossRef]

28. Sadowski, Ł.; Nikoo, M.; Nikoo, M. Principal component analysis combined with a self organization feature map to determine the pull-off adhesion between concrete layers. Constr. Build. Mater. 2015, 78, 386-396. [CrossRef]

29. Sadowski, Ł.; Hoła, J.; Czarnecki, S. Non-destructive neural identification of the bond between concrete layers in existing elements. Constr. Build. Mater. 2016, 127, 49-58. [CrossRef]

30. Archer, N.; Wang, S. Application of the back propagation neural network algorithm with monotonicity constraints for two-group classification problems. Decis. Sci. 1993, 24, 60-75. [CrossRef]

31. Lenard, M.; Alam, P.; Madey, G. The applications of neural networks and a qualitative response model to the auditor's going concern uncertainty decision. Decis. Sci. 1995, 26, 209-227. [CrossRef]

32. Veeramachaneni, K.; Peram, T.; Mohan, C.; Osadciw, L. Optimization Using Particle Swarms with Near Neighbor Interactions. In Genetic and Evolutionary Computation-GECCO 2003; Cantú-Paz, E., Foster, J.A., Deb, K., Eds.; Lecture Notes in Computer Science, Vol. 2723; Springer: Berlin, Heidelberg, Germay, 2003; pp. 110-121.

33. Khabbazi, A.; Atashpaz-Gargari, E.; Lucas, C. Imperialist competitive algorithm for minimum bit error rate beamforming. Int. J. Bio-Inspir. Comput. 2009, 1, 125-133. [CrossRef]

34. Kaveh, A.; Talatahari, S. Optimum design of skeletal structures using imperialist competitive algorithm. Comput. Struct. 2010, 88, 1220-1229. [CrossRef]

35. Lucas, C.; Nasiri-Gheidari, Z.; Tootoonchian, F. Application of an imperialist competitive algorithm to the design of a linear induction motor. Energy Convers. Manag. 2010, 51, 1407-1411. [CrossRef]

36. Talatahari, S.; Azar, F.B.; Sheikholeslami, R.; Gandomi, A.H. Imperialist competitive algorithm combined with chaos for global optimization. Commun. Nonlinear Sci. Numer. Simula. 2012, 17, 1312-1319. [CrossRef]

37. Xing, B.; Gao, W. Imperialist Competitive Algorithm. In Innovative Computational Intelligence: A Rough Guide to 134 Clever Algorithms; Springer International Publishing: Cham, Switzerland, 2014; pp. 203-209.

38. Tejani, G.G.; Savsani, V.J.; Patel, V.K. Adaptive symbiotic organisms search (SOS) algorithm for structural design optimization. J. Comput. Des. Eng. 2016, 3, 226-249. [CrossRef]

39. Rafiei, M.H.; Khushefati, W.H.; Demirboga, R.; Adeli, H. Neural Network, Machine Learning, and Evolutionary Approaches for Concrete Material Characterization. ACI Mater. J. 2016, 113, 781-789. [CrossRef]

40. Kaveh, A.; Nasrollahi, A. A new hybrid meta-heuristic for structural design: Ranked particles optimization. Struct. Eng. Mech. 2014, 52, 405-426. [CrossRef]

41. Alavi, A.H.; Hasni, H.; Zaabar, I.; Lajnef, N. A new approach for modeling of flow number of asphalt mixtures. Arch. Civ. Mech. Eng. 2017, 17, 326-335. [CrossRef]

42. Kaveh, A.; Nasrollahi, A. Engineering design optimization using a hybrid PSO and HS algorithm. Asian J. Civ. Eng. 2013, 14, 201-223.

43. Fedeliński, P.; Górski, R. Optimal arrangement of reinforcement in composites. Arch. Civ. Mech. Eng. 2015, 15, 525-531. [CrossRef]

44. Kaveh, A.; Nasrollahi, A. A new probabilistic particle swarm optimization algorithm for size optimization of spatial truss structures. Int. J. Civ. Eng. 2014, 12, 1-13.

45. Atashpaz-Gargari, E. Social optimization algorithm development and performance review. Master's Thesis, School of Electrical and Computer Engineering, Tehran University, Tehran, Iran, 2009. 
46. Atashpaz-Gargari, E.; Lucas, C. Imperialist competitive algorithm: An algorithm for optimization inspired by imperialistic competition. IEEE Congr. Evolut. Comput. 2007, 21, 4661-4667.

47. Hosseini-Moghari, S.M.; Morovati, R.; Moghadas, M.; Araghinejad, S. Optimum operation of reservoir using two evolutionary algorithms: Imperialist competitive algorithm (ICA) and cuckoo optimization algorithm (COA). Water Resour. Manag. 2015, 29, 3749-3769. [CrossRef]

48. Armaghani, D.J.; Hasanipanah, M.; Mohamad, E.T. A combination of the ICA-ANN model to predict air-overpressure resulting from blasting. Eng. Comput. 2016, 32, 155-171. [CrossRef]

49. Shirazi, A.Z.; Mohammadi, Z. A hybrid intelligent model combining ANN and imperialist competitive algorithm for prediction of corrosion rate in 3C steel under seawater environment. Neural Comput. Appl. 2016, 1-10.

50. Taghavifar, H.; Mardani, A.; Taghavifar, L. A hybridized artificial neural network and imperialist competitive algorithm optimization approach for prediction of soil compaction in soil bin facility. Measurement 2013, 46, 2288-2299. [CrossRef]

51. Ahmadi, M.; Ebadi, M.; Shokrollahi, A.; Majidi, S. Evolving artificial neural network and imperialist competitive algorithm for prediction oil flow rate of the reservoir. Appl. Soft Comput. 2013, 13, 1085-1098. [CrossRef]

52. Pourbaba, M.; Talatahari, S.; Sheikholeslami, R. A chaotic imperialist competitive algorithm for optimum cost design of cantilever retaining walls. KSCE J. Civ. Eng. 2013, 17, 972-979. [CrossRef]

53. Sadowski, L.; Nikoo, M. Corrosion current density prediction in reinforced concrete by imperialist competitive algorithm. Neural Comput. Appl. 2014, 25, 1627-1638. [CrossRef] [PubMed]

54. ASTM C1740-10 Standard Practice for Evaluating the Condition of Concrete Plates Using the Impulse-Response Method; ASTM: West Conshohocken, PA, USA, 2010.

55. Davis, A.G. The non-destructive impulse response test in North America: 1985-2001. NDT E E Int. 2003, 36, 185-193.

56. Ottosen, N.S.; Ristinmaa, M.; Davis, A.G. Theoretical interpretation of impulse response tests of embedded concrete structures. J. Eng. Mech. 2004, 130, 1062-1071. [CrossRef]

57. Sansalone, M.J.; Streett, W.B. Impact-echo: Nondestructive Evaluation of Concrete and Masonry; Bullbrier Press: Jersey Shore, PA, USA, 1997.

58. Schubert, F.; Köhler, B. Ten lectures on impact-echo. J. Nondestr. Eval. 2008, 27, 5-21. [CrossRef]

59. Carino, N.J. The impact-echo method: An overview. In Proceedings of the 2001 Structures Congress \& Exposition, Washington, DC, USA, 21-23 May 2001; pp. 21-23.

60. Gavin, J.; Holger, R.; Graeme, C. Input determination for neural network models in water resources applications. Part 2. Case study: Forecasting salinity in a river. J. Hydrol. 2005, 301, 93-107.

61. Dorofki, M.; Elshafie, A.H.; Jaafar, O.; Karim, O.A.; Mastura, S. Comparison of artificial neural network transfer functions abilities to simulate extreme runoff data. Int. Proc. Chem. Biol. Environ. Eng. 2012, 33, 39-44.

(C) 2017 by the authors. Licensee MDPI, Basel, Switzerland. This article is an open access article distributed under the terms and conditions of the Creative Commons Attribution (CC BY) license (http:/ / creativecommons.org/licenses/by/4.0/). 